\title{
Influence of Chromatographic Fractions of Extracts Derived From Bovine Neural Retina on Newt (Notophthalmus viridescens) Lens Regeneration In Vitro
}

\author{
THOMAS G. CONNELLY AND M. SEAN GREEN \\ Department of Anatomy and Cell Biology, The University of Michigan, \\ Ann Arbor, Michigan 48109-0010
}

\begin{abstract}
Removal of the ocular lens in adult newts (Notophthalmus viridescens) is followed by a series of cellular events leading to regeneration of a new lens by cell type conversion of pigmented iris epithelial cells at the dorsal pupillary margin (Yamada, Curr. Top. Dev. Biol. 2:247-283, 1967). Following depigmentation and five to seven cell divisions, iris epithelial cells redifferentiate into lens fiber cells and synthesize crystallin proteins (Yamada, Curr. Top. Dev. Biol. 2:247-283, 1967). This process is dependent upon neural retina in vivo (Stone, Anat. Rec. 131:151-172, 1958; Reyer, Dev. Biol. 14:214225,1966 ) and in vitro (Yamada et al., Differentiation 1:65-82, 1973). Acting on the hypothesis that the role of the neural retina is to promote passage of iris epithelial cells through the requisite number of cell cycles which will then allow them to redifferentiate as lens fiber cells (Yamada, in: Cell Biology of the Eye. Academic Press, New York, 1982), we undertook testing of the effects of eye-derived mitogenic substances, as well as other mitogens, on regeneration of lens from iris in organ culture. We have previously defined a critical period for the retinal influence in vivo and in vitro, and have shown that crude extracts of retina can enhance regeneration of lenses in culture (Connelly et al., J. Exp. Zool., 240:343-351, 1986). In this paper, we report on the lens regeneration enhancing activity (LRA) of more highly purified fractions of the retinal extracts. Heparin-sepharose chromatography of the crude retinal extract yields three fractions (Courty et al., Biochemie 67:265-269, 1985) called EDGF I, II, and III. EDGF I and II have affinity for heparin, while EDGF III does not. In our bioassay, LRA appears only in the EDGF III fraction. Dialysis of EDGF III against $0.1 \mathrm{~N}$ acetic acid yields a fraction which has affinity for cibacron blue sepharose (eluting at $2.15 \mathrm{M}$ salt) and also has significant LRA. Because insulin at high doses has a marginal effect on lens regeneration in culture (Williams and McGlinn, Am. Zool. 19:923, 1979; Connelly, Differentiation 16:85-91, 1980), we tested IGF-I. Because of the putative neurotrophic effects of transferrin (Tf) (Mescher and Munaim, J. Exp. Zool, 230:485-490, 1986), we tested $\mathrm{Tf}$ for its ability to enhance regeneration of the lens in culture. IGF-I seems to have an enhancing effect on lens regeneration; Tf does not.
\end{abstract}

Regeneration of the ocular lens in adult newts (Notophthalmus viridescens) is dependent upon the neural retina for its normal completion in vivo (Reyer, '66, '71; Stone, '58; Stone and Steinitz, '53). We have previously shown (Connelly et al., '86) that a critical period for the retinal influence on lens regeneration exists between 11 and 15 days after lentectomy. That is, removal of the retina on day 11 retards regeneration over a subsequent 7-day period, while removal of the retina on day 15 has no effect on lens regenerates attained by day 18 (Connelly et al., '86). It has been known for some time that initial events of lens regeneration (initiation of DNA synthesis, depigmentation, etc.) occur in culture in the absence of the retina (Eguchi, '67; Eisenberg-Zalik and 
Scott, '69; Jauker and Yamada, '73; Reese, 73). These data suggest that the retina acts to facilitate the conversion of depigmented iris epithelial cells into lens fiber cells, rather than acting in the early phases of the regeneration process (Yamada, '82, '84).

Regeneration of the lens will take place in vitro under a variety of conditions (Connelly et al., '73; Yamada et al., '73; Connelly, '77). In the experiments of Yamada et al. ('73), newt iris pieces were cultivated in contact with frog tadpole neural retina by implanting the iris into the optic cavity of tadpole eyeballs after removal of cornea, lens, and adhering sclera. 'These were then cultured in a standard organ culture environment. This model was similar to that of 'Zalokar ('44). In the experiments of Yamada et al. (73), however, it was possible to determine that the regenerates definitely formed from the newt iris (rather than lens epithelial cells remaining in the optic cavity) because of clear morphological differences between frog and newt cells.

The experiments of Connelly et al. ('73) showed that the ability to enhance lens regeneration in culture was not unique to the retina, but could be duplicated by the pituitary gland. The exact nature of the pituitary influence is unknown and could not be duplicated by addition of a number of hormones to the culture medium (Connelly, ' 80 ). The only hormone which showed even a marginal enhancing effect, insulin, is not of pituitary origin (Williams and McGlinn, '79; Connelly, '80). Other researchers (Cuny and Zalik, '81; Cuny et al., '84) presented evidence which showed that TSH could enhance lens regeneration in culture, but this was subsequently shown to be due to the presence of some unknown contaminant in the TSH preparations used (Cuny and Zalik, '85). FGF was also tested and found to have no effect on lens regeneration.

Hypophysectomy markedly reduces thymidine labeling in the dorsal iris epithelium after lentectomy (Connelly et al., '73), and the presence of the pituitary in organ culture markedly enhances thymidine incorporation by dorsal iris epithelial cells (Connelly, un. published observations). Removal of the neural retina has a marked effect on thymidine incorporation by iris epithelial cells (Reyer, '66). These observations suggest that the most compelling link between the ability of these two divergent organs to enhance lens regeneration is a possible influence on cell proliferation. Yamada ('82,'84), McAvoy ('81), and Beebe ('85) have suggested that the role of the retina is to help promote the passage of the iris epithelial cells through the requisite number of cell cycles, which will then allow them to redifferentiate into lens cells. Although it is possible that the pituitary and the retina may produce the same effect in culture by different means, it is also possible that they produce a similar activity. Because the iris and retina are normally in close relationship to each other during regeneration in vivo, we thought it was more appropriate to investigate this interaction further. Testing eye-derived mitogenic substances seemed, therefore, logical and appropriate.

In an earlier paper (Connelly et al., '86), we showed that it was possible to enhance regeneration of a lens in organ culture by adding crude extracts of neural retina to the culture medium. Extracts were prepared according to the method of Courty et al. ('85). Recently, Cuny et al. ('86) have reported similar results on the influence of EDGF preparations on regeneration of lenses in irises cultured from the day of lentectomy. Our experiments reported here show the effects of a number of chromatographic fractions of a similar crude extract on lens regeneration in culture, but concentrate on the effects of these fractions on regeneration of the lens during the "critical period" of regeneration. Although working on the same basic hypothesis, our results are somewhat different.

Insulin-like growth factor-I (IGF-I, somatomedin C) enhances proliferation of lens epithelial cells in frogs (Rothstein et al., '80) and mammals (Reddan and Dziedzic, 82), and insulin marginally enhances regeneration in culture (Connelly, '80). Since it has been suggested that transferrin (Tf; human transferrin-h-Tf) may be a carrier protein for IGF-I, (Ezban et al., '79), and since Tf has been strongly implicated as a neurotrophic agent in amphibian limb regeneration (Mescher and Munaim, '84; Munaim and Mescher, '86), we also elected to test the effects of IGF-I and $\mathrm{Tf}$ on lens regeneration in culture.

\section{MATERIALS AND METHODS General Methods}

Newts (Notophthalmus viridescens) obtained from Bill Lee's Newt Farms (Oak Ridge, $\mathrm{TN}$ ) maintained at $21^{\circ} \mathrm{C}$ were used in all experiments. Animals were anesthetized in a 1:1,000 aqueous solution of ethyl-m-aminobenzoate methane sulfonate (EAMS; Sigma, St. Louis, MO) prior to any surgery. For simple lens removal, animals were anes- 
thetized, small paper plugs were inserted into their mouths to put gentle pressure on their eyeballs from the oral side, and a single nasotemporal incision at the equator of the eye was made through the cornea with a \#11 scalpel blade. By exerting gentle pressure on the eye with watchmakers forceps, the experimenter can express the lens from the optic cavity. When this is done correctly, no damage to the iris occurs, no bleeding is induced, and animals can be returned immediately to their tanks for recovery.

For organ culture experiments, animals were soaked for $30 \mathrm{~min}$ in a weak $(5-10 \mathrm{mg} /$ L) solution of $\mathrm{KMnO}_{4}$ (Rounds, '73; Connelly, '77), anesthetized as above (including the placement of mouth plugs), and then their heads and eyes were rinsed for about $30 \mathrm{sec}$ in a steady stream of $70 \% \mathrm{ETOH}$, followed by a brief rinse with sterile distilled water. All subsequent operations were performed in a laminar flow hood.

At 11 days after lens removal, animals were prepared as described above, and a small incision was made at the corneo-scleral junction with a \#11 scalpel blade. Using small iridectomy scissors this incision was extended around the circumference of the eye at the corneo-scleral junction, and the entire irido-corneal complex was then lifted off the eye. The irido-corneal complexes (ICCs) were rinsed in complete culture medium (containing $50 \mu \mathrm{g} \mathrm{ml}$ of gentamicin; see below) and then explanted to an organ culture environment as described previously (Connelly, '77). These irido-corneal complexes were then cultured for 10 days (21 days total regeneration time). Usually 3-5 ICCs were fixed at the time of explantation to determine the stage of regeneration attained by the group at the initiation of the experiment.

When extracts were added to the culture medium, aliquots of the extracts were sterilized by filtration, and the protein concentration of each was then determined using the Lowry method.

\section{Organ culture methods}

Basic methods of culturing newt ICCs used in this laboratory for several years were also used here. Culture medium consisted of $50 \%$ Leibovitz L-15 medium (GIBCO, Grand Island, NY), $40 \%$ sterile glass distilled water, $10 \%$ fetal calf serum (HyClone, Logan, UT), $50 \mu \mathrm{g} / \mathrm{ml}$ gentamicin (GIBCO), and $5 \mathrm{mM}$ Hepes (Sigma). ICCs were explanted onto filter paper supports (Gelman Metricel GN-6, Gelman Sciences, Ann Arbor, MI). The filter papers were, in turn, supported by a triangular stainless steel mesh which dipped into the central well of an organ culture dish (Falcon Plastics). Culture medium was placed in the central well to a level which just wets the stainless steel grid, wetting the filter paper, and covering the ICCs with a very thin layer of moisture. Cultures were maintained at $25^{\circ} \mathrm{C}$ in an incubator and humid chambers. IGF-I was purchased from AMGEN Biochemicals (Thousand Oaks, CA) and transferrin was human transferrin (Tf; h-Tf) purchased from Sigma.

\section{Histological methods}

Cultures were evaluated histologically. Filter papers with adherent ICCs were fixed in Bouin's fluid overnight. They were then dehydrated through a graded series of ethanols to $100 \%$, cleared in methyl salicylate, infiltrated and embedded in paraffin. Serial 10 $\mu \mathrm{m}$ sections were prepared and mounted on subbed slides. After deparaffinization, sections were stained with hematoxylin and eosin, and regenerates were evaluated for stage attained according to Yamada's (67) modification of Sato's staging system.

We define Sato stage $V$ and below as being undifferentiated; although the iris may be depigmented and proliferating, there is no morphologic indication of lens-specific differentiation. Regenerates which have attained Sato stage VI or later are considered to be differentiating as lens. The validity of our morphological staging has been confirmed by detection of gamma crystallins (Connelly et al., '86). Extracts were considered to have positive lens regeneration activity (LRA) if a significant number of advanced stages were produced as compared to untreated controls. Although the data are presented here as though only two classes of regenerates were obtained (pre-stage VI and post-stage VI), statistical analysis is actually carried out on the raw data in which regenerates are assigned to stages ranging from Sato stage II to Sato stage X. Statistical analysis of data was carried out using the Mann-Whitney $U$ test via the University of Michigan's MIDAS statistical package written and supported by the Statistical Research Laboratory.

\section{Preparation of extracts}

A flow chart outlining the basic procedure for preparing extracts and extract fractions is presented in Figure 1. Extracts of 300-500 neural retinas from adult bovine eyes (Monarch Packing, Detroit, MI) were prepared. 
BOVINE RETINA

CRUDE HOMOGENATE

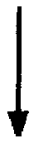

$20 \%-60 \%\left(\mathrm{NH}_{4}\right)_{2} \mathrm{SO}_{4}$

FRACTIONATION

HEPARIN SEPHAROSE

CHROMATOGRAPHY

0.1N ACETIC ACID

DIALYSIS

\{PRECIPITATE\}

0.1N HAC DIALYSATE $\triangle$

$\{0.90 \mathrm{M} \mathrm{NaCl}\}$ •

$\{1,40 \mathrm{M} \mathrm{NaCl}\} \cdot$

$0.65 \mathrm{M} \mathrm{NaCl} \Delta$

1

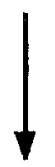

BLUE SEPHAROSE

$\{0.154 \mathrm{M} \mathrm{NaCl}\} \cdot$

CHROMATOGRAPHY

$2.150 \mathrm{M} \mathrm{NaCl} A$

$\Delta$ enhances lens regeneration

- does not enhance lens regeneration

Fig. 1. Flow chart describing the basic procedure for preparation of extracts and extract fractions. Fractions in brackets were not further purified. For some experiments, the order in which extract was taken over the affinity columns was reversed, and the acid dialysis was omitted. 
All steps were carried out on ice or at $4^{\circ} \mathrm{C}$, unless otherwise specified. The eyes were incised at the limbus around most of their circumference with a \#11 scalpel blade, and the lens and the vitreous were removed by simply turning the eyeball inside out. The neural retina was removed from its attachments by gentle teasing with blunt forceps. Retinas were placed immediately into ice-cold PBS until homogenized. Retinas were homogenized in a Dounce homogenizer in equal volumes of PBS. The homogenate was then centrifuged at $20,000 \times \mathrm{g}$ for $20 \mathrm{~min}$ in a Beckman A-19 rotor to remove cellular debris and any adherent pigment removed at the dissection. The supernatant was then spun at $100,000 \times \mathrm{g}$ for $2 \mathrm{hr}$ in a Beckman Ti-42 rotor. The supernatant from this spin was called the crude homogenate.

To prepare a crude extract (CE) of the homogenate, ammonium sulfate was added to the supernatant of the $100,000 \times \mathrm{g}$ spin to a final concentration of $0.8 \mathrm{M}$. This solution was centrifuged at $20,000 \times \mathrm{g}$ for $30 \mathrm{~min}$, and any pellet found was discarded. The supernatant was then brought to a final concentration of $2.5 \mathrm{M}$ ammonium sulfate. The flocculent material precipitated at this step was pelleted by a 30 -min centrifugation at $20,000 \times \mathrm{g}$. The supernatant was discarded and the pellet dissolved in PBS. This solution was then dialyzed for 1-2 days against 4-6 liters of $0.154 \mathrm{M} \mathrm{NaCl}$ at $4^{\circ} \mathrm{C}$.

\section{Cibacron blue chromatography}

Crude extract was fractionated on a column of cibacron blue sepharose (Pharmacia, Piscataway, NJ) after the method of Barritault et al. ('82). A maximum of $29 \mathrm{mg}$ of CE/ $\mathrm{ml}$ of the gel was applied to a column equilibrated with PBS. Flow rate during sample application was $10 \mathrm{ml} / \mathrm{cm}$ (linear flow rate). The column was washed with PBS and eluted with $0.65 \mathrm{M} \mathrm{NaCl}$, and then with $2.15 \mathrm{M}$ $\mathrm{NaCl}$ (presumably containing Courtois' EDGF I and II), and finally with $2 \mathrm{M} \mathrm{NaCl} / 2$ $M$ urea (to regenerate the column) at a flow rate of $25 \mathrm{ml} / \mathrm{cm}$. Protein concentration was measured by the method of Bradford using bovine gamma globulin as a standard. Samples were stored at $-20^{\circ} \mathrm{C}$ in elution buffer.

\section{Acid purification}

Part of the published purification procedure for EDGF involves dialysis of the CE or column fractions against $0.1 \mathrm{~N}$ acetic acid. In our laboratory this was accomplished by dialyzing aliquots of the CE against several liters of $0.1 \mathrm{~N}$ acetic acid overnight in the cold.
Prior to use in the organ culture assay, the dialyzate was neutralized with $1 \mathrm{M} \mathrm{NaOH}$ and $10 \mathrm{mM}$ Hepes. Protein content of the dialyzate was then determined.

\section{Heparin chromatography}

Passage of the crude extract or the blue column fractions over a heparin sepharose column is thought to remove EDGF I and II from the extract (Courty et al., '85). Samples were applied to a heparin column at a maximum loading of $64 \mathrm{mg} / \mathrm{ml}$ of gel. After washing with $0.65 \mathrm{M} \mathrm{NaCl}$ (presumably eluting "EDGF' III"), other fractions were eluted with $0.9 \mathrm{M}$ salt (presumably eluting EDGF II) (Courty et al., '85) and 1.4 M salt (presumably eluting EDGF I) (Courty et al., '85).

\section{Mitogenic assay}

As in our previous paper (Connelly et al, '86), we tested the mitogenicity of each fraction obtained using a modification of the procedures of Barritault et al. ('82) and Plouet et al, (84). Bovine corneal endothelial (BCE) cells, originally established in culture by Drs. Donald MacCallum and John Lillie (Department of Anatomy and Cell Biology, The University of Michigan), were used as test cells for mitogenicity of the various fractions obtained from retinal extract. Serially subcultured BCE cells ( $2-5$ passages in medium containing no added growth factors) were seeded at a density of $1 \times 10^{3}$ cells per well into 96-well plates (Falcon), Culture medium consisted of either MEM or M-199 (Gibco) supplemented with $2 \mathrm{mM}$ L-glutamine, $10 \%$ FCS, $50 \mu \mathrm{g}$ per $\mathrm{ml}$ gentamicin, and $10 \mathrm{mM}$ Hepes. After $72 \mathrm{hr}$, fractions to be tested (along with appropriate buffer controls) were added to individual test wells in volumes of 2-15 $\mu$ l. After a 24 -hr incubation period, the process was repeated. Twenty-four hours later, cells were labeled with ${ }^{3} \mathrm{H}$-thymidine $(0.2 \mu \mathrm{li} /$ well $)$ for $4 \mathrm{hr}$. The cell monolayers were then washed three times with PBS and lysed overnight in $0.5 \mathrm{M} \mathrm{NaOH}$ in $1 \%$ SDS. The lysate was then neutralized with $1 \mathrm{M}$ $\mathrm{HCl}$ and counted in $4 \mathrm{ml}$ of ACS scintillation cocktail (Amersham) in a Beckman LS-9000 spectrometer (Lillie et al., '82). If fractions were still mitogenic under these test conditions, yet produced no LRA, we interpreted these results as indicating the extract had not been damaged.

\section{RESULTS}

Previous results (Connelly et al., '86) showed that material which binds to cibacron blue and elutes at $2.15 \mathrm{M}$ salt is about 


\section{Controls}

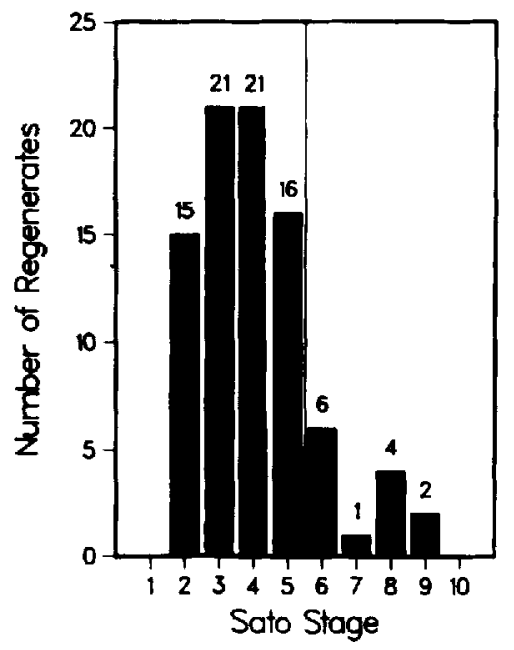

Crude Extract $500 \mathrm{ug} / \mathrm{ml}$

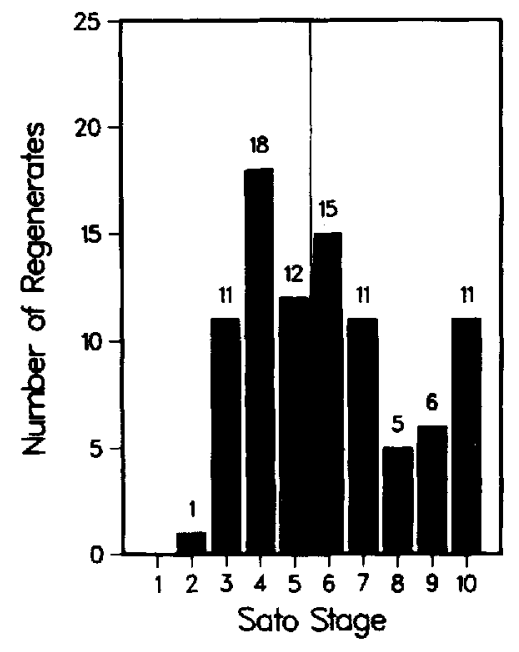

Fig. 2. Stages attained by regenerates from (a) control cultures and (b) crude extract $500 \mu \mathrm{g} i$ $\mathrm{ml}$ cultures. The number of regenerates in the group at each stage are represented by the bars. Data are pooled from several assays.

20 times more effective in enhancing lens regeneration than the $\mathrm{CE}$. Figure 2 shows the range of stages attained by untreated regenerates and regenerates treated with crude extract $(500 \mu \mathrm{g} / \mathrm{ml})$. One can see that a treatment which is significantly effective in LRA generally pushes regenerates to more advanced stages even in the range we consider below the cutoff for lens-specific redifferentiation (Sato stage VI). Tables 1-3 show the effects of other purification steps on LRA of the retinal material(s).

Because the material binding to the blue column presumably contains EDGF I and II, we tested the material which also binds to heparin sepharose for its ability to stimulate lens regeneration. Fractions eluting from heparin sepharose at $1.4 \mathrm{M} \mathrm{NaCl}$ (presumably containing EDGF I (Courty et al., '85) or at $0.9 \mathrm{M} \mathrm{NaCl}$ (presumably containing EDGF II) (Courty et al., '85) did not possess LRA in the doses tested (Table 1). We chose the doses based on the effective doses for CE and the relative proportion of the protein content of $\mathrm{CE}$ represented by the column fractions. The run through wash $(0.65 \mathrm{M}$ $\mathrm{NaCl}$ fraction; EDGF III) from the heparin column was roughly as active as the crude extract (Table 1). Dialysis of the crude extract against $0.1 \mathrm{~N}$ acetic acid did not destroy the LRA of the extract (Table 2). If the 0.65 $\mathrm{M} \mathrm{NaCl}$ run through wash from the heparin column was dialyzed against acetic acid and then passed over a cibacron blue column, material bound to the blue column and eluted from that column at $2.15 \mathrm{M} \mathrm{NaCl}$. The fraction which this procedure yielded was estimated to be 20 to 100 times as active as the CE (Table 2). In terms of total protein, this fraction is approximately $0.06 \%$ of the starting material (CE). Fractions obtained by sequential chromatography on blue sepharose and heparin sepharose (without acid dialysis) also yielded an active fraction that did not bind to heparin (Table 2). Precise activity comparisons are not possible because of the inherent variability of the assay system and the difficulty in obtaining large numbers of cases.

Addition of IGF-I to the organ culture medium produced a modest enhancement of lens regeneration in culture (Table 3). IGF-I seemed to have peak activity at about $30 \mathrm{ng} /$ $\mathrm{ml}$. A transferrin dose of $50 \mu \mathrm{g} / \mathrm{ml}$ was chosen since this appears to be the optimum dose for enhancement of thymidine incorporation by newt limb blastema cells in culture (Munaim and Mescher, '86; Mescher, personal communication). Figure 3 shows the range of stages attained by regenerates treated with $\mathrm{h}-\mathrm{Tf}(50$ $\mu \mathrm{g} / \mathrm{ml})$ or IGF-I $30(30 \mathrm{ng} / \mathrm{ml})$. Neither of these substances, in the doses tested, produced as marked an enhancement of regeneration as some of our retinal extract fractions, yet ad- 
TABLE 1. Influence of crude extract heparin sepharose fractions on the progress of lens regeneration in vitro $^{\mathrm{a}}$

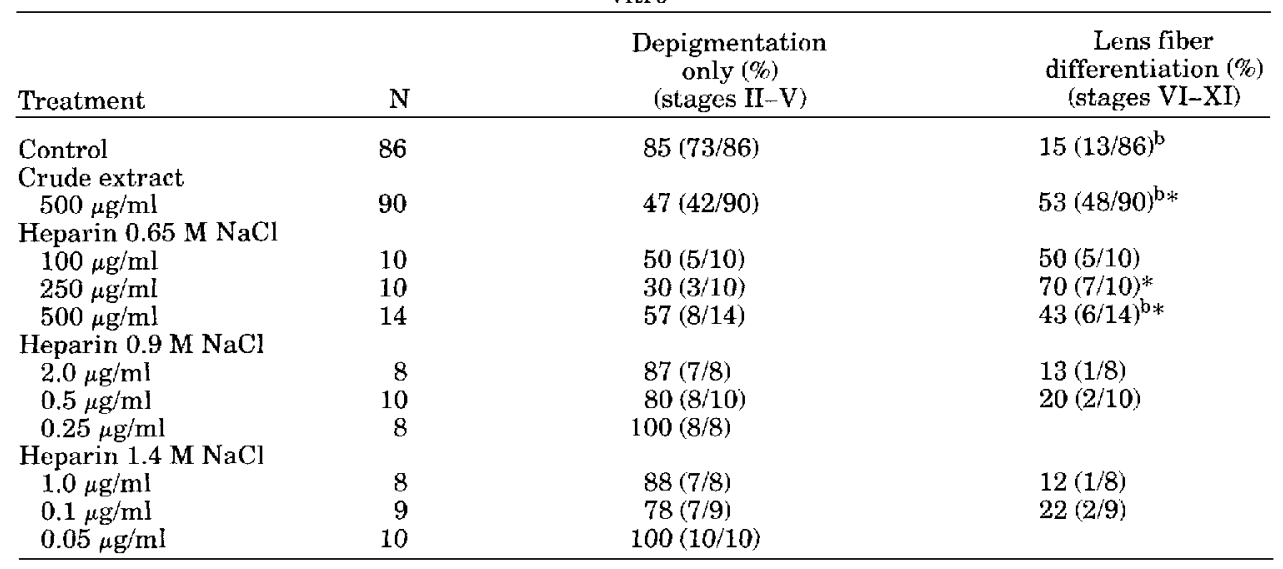

aridocorneal complexes were cultured from day 11 to day 21 post-lentectomy.

${ }^{\text {b}}$ Data are pooled results from more than one assay.

* Significant $(p<0.05)$ difference from pooled controls.

TABLE 2. Influence of various fractions on the progress of lens regeneration in vitro

\begin{tabular}{|c|c|c|c|}
\hline Treatment $^{\mathrm{a}}$ & $\mathbf{N}$ & $\begin{array}{c}\text { Depigmentation } \\
\text { only (\%) } \\
\text { (stages II-V) }\end{array}$ & $\begin{array}{c}\text { Lens fiber } \\
\text { differentiation }(\%) \\
\text { (stages VI-XI) }\end{array}$ \\
\hline Control & 86 & $85(73 / 86)$ & $15(13 / 86)^{b}$ \\
\hline $\mathrm{CE} 500 \mu \mathrm{g} / \mathrm{ml}$ & 90 & $47(42 / 90)$ & $53(48 / 90)^{b *}$ \\
\hline $\begin{array}{l}\text { CE AC } \\
\qquad 100 \mu \mathrm{g} / \mathrm{ml}\end{array}$ & 10 & $30(3 / 10)$ & $70(7 / 10)^{*}$ \\
\hline \multicolumn{4}{|l|}{$\mathrm{H} .65 \mathrm{AC}$} \\
\hline $\mathrm{B} 2.155 \mu \mathrm{g} / \mathrm{ml}$ & 8 & $50(4 / 8)$ & $50(4 / 8)$ \\
\hline B2.15 H.65 & & & \\
\hline $10 \mu \mathrm{g} / \mathrm{ml}$ & 6 & $50(3 / 6)$ & $50(3 / 6)$ \\
\hline \multicolumn{4}{|l|}{ B2.15 H.65 } \\
\hline $25 \mu \mathrm{g} / \mathrm{ml}$ & 10 & $30(3 / 10)$ & $70(7 / 10)^{*}$ \\
\hline
\end{tabular}

${ }^{a} \mathrm{CE}$ : crude extract; H: heparin sepharose fraction; $\mathrm{AC}$ : acid cut (dialysate from $0.1 \mathrm{~N}$ HAc dialysis); B: blue sepharose fraction. Example: H.65 AC B2.15 fraction is the $0.65 \mathrm{M} \mathrm{NaCl}$ fraction from chromatography of crude extract on heparin sepharose, dialyzed vs. $0.1 \mathrm{~N}$ HAc and neutralized, then fractionated on blue sepharose and the $2.15 \mathrm{M} \mathrm{NaCl}$ fraction retained.

bata are pooled results from more than one assay.

*Significant $(p<0.05)$ difference from pooled controls.

TABLE 3. Influence of IGF-I and transferrin on the progress of lens regeneration in vitro ${ }^{\mathrm{a}}$

\begin{tabular}{|c|c|c|c|}
\hline Treatment & $\mathrm{N}$ & $\begin{array}{c}\text { Depigmentation } \\
\text { only (\%) } \\
\text { (stages II-V) }\end{array}$ & $\begin{array}{c}\text { Lens fiber } \\
\text { differentiation (\%) } \\
\text { (stages VI-XI) }\end{array}$ \\
\hline Control & 86 & $85(73 / 86)$ & $15(13 / 86)^{b}$ \\
\hline $\begin{array}{l}\text { Crude extract } \\
500 \mu \mathrm{g} / \mathrm{ml}\end{array}$ & 90 & $47(42 / 90)$ & $53(48 / 90)^{\mathrm{b} *}$ \\
\hline $\begin{array}{l}15 \mathrm{ng} / \mathrm{ml} \\
30 \mathrm{ng} / \mathrm{ml} \\
50 \mathrm{ng} / \mathrm{ml}\end{array}$ & $\begin{array}{l}13 \\
12 \\
20\end{array}$ & $\begin{array}{l}69(9 / 13) \\
50(6 / 12) \\
85(17 / 20)\end{array}$ & $\begin{array}{l}31(4 / 13) \\
50(6 / 12)^{*} \\
15(3 / 20)^{b}\end{array}$ \\
\hline $\begin{array}{l}\text { CE } 500 \mu \mathrm{g} / \mathrm{ml}+ \\
\text { anti-IGF-I } 100 \mathrm{nM} \\
\text { h-Transferrin }\end{array}$ & 6 & $33(2 / 6)$ & $67(4 / 6)^{*}$ \\
\hline $\begin{array}{l}5 \mu \mathrm{g} / \mathrm{ml} \\
50 \mu \mathrm{g} / \mathrm{ml} \\
100 \mu \mathrm{g} / \mathrm{ml}\end{array}$ & $\begin{array}{l}16 \\
46 \\
10\end{array}$ & $\begin{array}{l}87(14 / 16) \\
78(36 / 46) \\
90(9 / 10)\end{array}$ & $\begin{array}{l}13(2 / 16)^{\mathrm{b}} \\
22(10 / 46)^{\mathrm{b}} \\
10(1 / 10)\end{array}$ \\
\hline
\end{tabular}

${ }^{\text {a }}$ Iridocorneal complexes were cultured from day 11 to day 21 post-lentectomy.

'Data are pooled results from more than one assay.

*Significant $(\mathrm{p}<0.05)$ difference from pooled controls. 

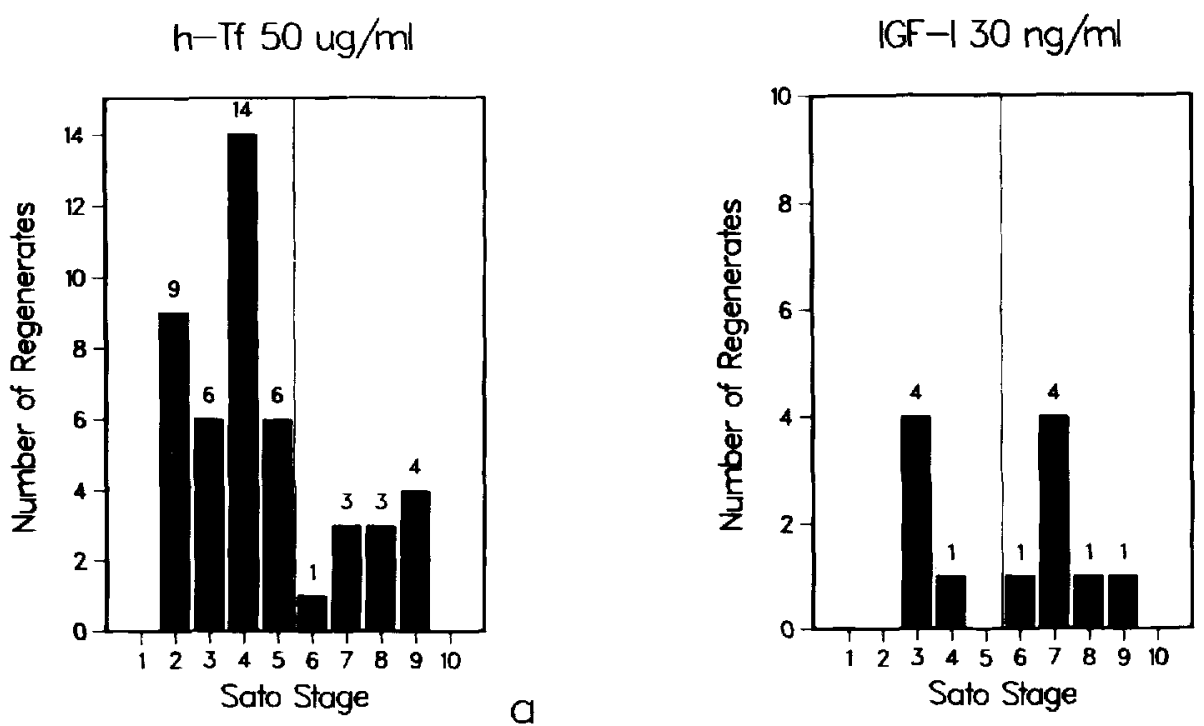

Fig. 3. Stages attained by regenerates from (a) h-Tf $50 \mu \mathrm{g} / \mathrm{ml}$ treated cultures and (b) IGF-I $30 \mathrm{ng} / \mathrm{ml}$ treated cultures. The number of regenerates in the group at each stage are represented by the bars. Data for (a) are pooled from several assays; (b) represents a single assay.

vanced regenerates formed under the influence of either IGF-I or transferrin can exhibit excellent morphology. Regenerates produced under the influence of IGF-I were beyond our stage $\mathrm{V}$ bound for indication of LRA, but fewer very advanced regenerates (stage IX or later) were found in IGF-I-treated cultures than in CE-treated cultures (Fig. 2). Although treatment with $\mathrm{h}$-Tf produced several advanced regenerates, the range of stages was similar to control cultures and dramatically different from CE-treated cultures (Fig. 2). Similar results were obtained when irises were explanted on day 0 rather than on day 11 and cultivated for 21 days in the presence or absence of the various test factors (Table 4).

Heat treatment of the CE destroyed its LRA, while treatment with trypsin reduced but did not destroy activity (data not shown). These results seem to parallel those of Campbell and McAvoy ('86), who have shown that fiber differentiation factor (FDF) derived from bovine-retina conditioned medium, is also trypsin-resistant.

\section{DISCUSSION}

The experiments described here show that the LRA of retinal extracts is not due to the
EDGF I and II components of the extract. The material(s) which promotes lens regeneration in cultures of regenerates explanted during the critical period (Connelly et al., '86) has affinity for cibacron blue gel, but does not have affinity for heparin sepharose (e.g., EDGF III of Courty et al., '85). It is now known that EDGF I and II correspond to acidic and basic fibroblast growth factor (FGF) (Schreiber et al., '85; Courty et al., '85). Our results, therefore, confirm and support those of Cuny and Zalik ('85) who found FGF to have no effect on lens regeneration in culture. Our results do not, however, agree with those of Cuny et al. ('86) with respect to EDGF II. Because Cuny et al. ('86) use a much lower cut-off point for assessing enhancement of regeneration, the difference may be one of interpretation. In our experiments, regenerates must progress beyond stage $V$ before we consider them advanced. Under our culture conditions, it is not uncommon for up to $50 \%$ of irises explanted at day zero to progress to stage $\mathrm{V}$ in the absence of any additional treatment. We interpret their data for EDGF I and II as showing little or no effect of the treatment. Experiments with EDGF III rechromatographed on a heparin sepharose column show only traces of 
TABLE 4. Influence of retinal extract on the progress of lens regeneration in vitro from 0 to 21 days ${ }^{\mathrm{a}}$

\begin{tabular}{lclc}
\hline Treatment & N & $\begin{array}{c}\text { Depigmentation } \\
\text { only (\%) } \\
\text { (stages II-V) }\end{array}$ & $\begin{array}{c}\text { Lens fiber } \\
\text { differentiation (\%) } \\
\text { (stages VI-XI) }\end{array}$ \\
\hline Control & 20 & $95(19 / 20)$ & $5(1 / 20)^{\mathrm{b}}$ \\
CE $500 \mu \mathrm{g} / \mathrm{ml}$ & 14 & $36(5 / 14)$ & $64(9 / 14)^{*}$ \\
h-Tf $50 \mu \mathrm{g} / \mathrm{ml}$ & 9 & $78(7 / 9)$ & $22(2 / 9)$ \\
CE $500 \mu \mathrm{g} / \mathrm{ml}+$ & 17 & $24(4 / 17)$ & $76(13 / 17)^{\mathrm{b} *}$ \\
h-Tf $50 \mu \mathrm{g} / \mathrm{ml}$ & & & \\
\hline
\end{tabular}

"Iridocorneal complexes were cultured from day 0-21 post-lentectomy.

${ }^{b}$ Data are pooled results from more than one assay.

*Significant $(\mathrm{p}<0.05)$ difference from pooled controls.

heparin binding material $(\sim 50 \mu \mathrm{g} / 1,000 \mathrm{mg})$ and no loss of activity in the rechromatographed preparation.

Our initial results with crude retinal extract and the $2.15 \mathrm{M}$ salt fraction from the cibacron blue column (Connelly et al., '86) made us suspect that EDGF I and II were the most likely factors responsible for the LRA. Positive effects of EDGF I and II would have been most encouraging since pituitary glands are a rich source of FGF and since EDGF I and II are FGF-like molecules (for review, see Gospodarowicz et al. '86). Unfortunately, our results do not help us to determine if the similar effects of the pituitary and the neural retina are due to the fact that both organs produce similar material(s) which enhance regeneration, or if they produce different material(s) acting on a common event in the pathway of cell type conversion.

Our results also show that IGF-I was able to enhance lens regeneration in culture to a limited extent. At high doses (50 ng/ml), IGFI may be inhibitory (Table 3). Treatment of our CE with antibody to IGF-I (graciously supplied by Dr. J. Van Wyk) had no effect on the efficacy of our CE to produce advanced lens regenerates in the critical-period bioassay (Table 3). These results are interesting from the standpoint of regenerative neurotrophism in general, as well as from the standpoint of the effects of IGF-I on mitosis and cell differentiation in the frog lens (Rothstein et al., '80).

Although IGF-I produced a modest enhancement of regeneration, the numbers of advanced regenerates (beyond stage V) were not consistently as high as those produced by treatment with retinal extracts. Some rather striking regenerates were produced. Stimulation of mitosis alone may not be sufficient to cause marked enhancement of regeneration in culture; perhaps some other activity present in retinal extract is responsible for its greater potency. Any such activity might act by modulating IGF-I receptors or by a completely different mechanism.

Transferrin is known to be mitogenic for cells of amphibian regeneration (Mescher and Munaim, '84; Munaim and Mescher, '86). Consequently, we considered it to be a likely potential candidate for enhancement of lens regeneration. Our data show, however, that Tf has relatively little effect on the progress of lens regeneration in culture or on stimulation of DNA synthesis in iris epithelia (Connelly and Green, unpublished). If one looks carefully at Mescher's data, it is possible to interpret his results as demonstrating the efficacy of $\mathrm{Tf}$ as a serum replacement. Although Tf/ $1 \%$ serum can bring thymidine incorporation levels in newt blastema cells up to levels found with $10 \%$ serum alone, that is not enough to support regeneration in long-term culture. Consequently, we question whether such data from blastema cultures indicate anything about the potential trophic nature of Tf (or other factors tested). In the lens system, we have found a positive correlation between ability to stimulate DNA synthesis and enhancement of lens regeneration, as indicated by the formation of advanced lens regenerates in short- or longterm cultures.

Although we know that crude extract enhances incorporation of thymidine by lens regenerates in culture, we do not yet know how this translates into effects on mitotic index or cell cycle time in the cells of the regenerate. Nor do we yet have data regarding the effects of the various fractions of the retinal extract on these parameters. Experiments of this type are hampered by the lack 
of a mitogenicity assay for newt ocular cells comparable to the BCE assay described above. The TVI cell line (derived from newt iris epithelium) of Reese et al. ('76) has been lost (Yamada, personal communication). We have cultured iris epithelial cells in tissue culture from primary explants, but are unable to produce sufficient numbers of such cells for routine use in mitogenicity assays. Cells in such cultures have extremely long cell cycle times (approximately $80 \mathrm{hr}$ ) (Yamada, '84) and are difficult to maintain since they routinely begin to produce lentoids and then degenerate slowly over time (even in the absence of external factors).

Two other factors which appear to be involved in control of fiber differentiation are lentropin (Beebe et al., '80) and FDF (Campbell and McAvoy, '86). Since lentropin activity is inhibited by antibodies to IGF-I (Beebe, '85) and because of the marginal effects of IGF-I on our system, we suspect that what we are looking at is probably not a lentropinlike substance. FDF is a very high molecular weight material which may be an aggregate of several components of somewhat lower molecular weight whose activity is resistant to trypsin (Campbell and McAvoy, '86). FDF is also a material derived from conditioned medium rather than directly from homogenates of retina. Recent results show that FDF activity can be mimicked by EDGF 1 and 11 (Chamberlain and McAvoy, '87). Consequently it is not possible at this time to make any inferences regarding the relationship of the activity we are studying to FDF.

\section{ACKNOWLEDGMENTS}

The authors wish to thank Ms. Brigit Mary McGowan for technical assistance and Ms. Joyce Morris-Wiman for critical reading of the manuscript. This research was supported by grant 1 R01-EY-05419 (T.G.C.) from the Public Health Service, National Institutes of Health.

\section{LITERATURE CITED}

Barritault, D., J. Plouet, J. Courty, and Y. Courtois (1982) Purification, characterization and biological properties of the eye derived growth factor from retina. Analogies with brain derived growth factor. J. Neurosci. Res., 8:477-490.

Beebe, D. (1985) Ocular growth and differentiation factors. In: Growth and Maturation Factors, Volume 3. G. Guroff, ed. John Wiley and Sons, pp 39-76.

Beebe, D., D.E. Feagans, and H.A.H. Jebens (1980) Lentropin: A factor in vitreous humor which promotes lens fiber cell differentiation. Proc. Natl. Acad. Sci. USA, 77:490-493.
Campbell, M.T. and J.W. McAvoy (1986) A lens fiber differentiation factor from calf neural retina. Exp. Cell Res., 163:453-466.

Chamberlain, C.C. and J.W. McAvoy (1987) Fibroblast growth factors promote lens fiber differentiation. Invest. Opthalmol. Vis. Sci. Suppl., 28(3):84.

Connelly, T.G. (1977) Pituitary enhancement of Wolffian lens regeneration in vitro: Spatial and temporal requirements. J. Exp. Zool., 200:359-364.

Connelly, T.G. (1980) 'The influence of hormones and other substances on lens regeneration in vitro, Differentiation, 16:85-91.

Connelly, 'T.G., M.S. Green, W.M. Sahijdak, and R.M. Loyd (1986) Role of the neural retina in newt (Notophthalmus viridescens) lens regeneration in vitro. J Exp. Zool., 240:343-351.

Connelly, T.G., J.R. Ortiz, and T. Yamada (1973) Influence of the pituitary on Wolffian lens regeneration. Dev. Biol., 31:301-315.

Courty, J., C. Loret, M. Moenner, B. Chevallier, O. Lagente, Y. Courtois, and D. Barritault (1985) Bovine retina contains three growth factor activities with different alfinity to heparin: Eye derived growth factor, I, II, III. Biochimie, 67:265-269.

Cuny, R., J.C. Jeanny, and Y. Courtois (1986) Lens regeneration from cultured newt irises stimulated by retinaderived growth factors. Differentiation 32:221-229.

Cuny, R. and S.E. Zalik (1981) Effect of bovine pituitary hormone preparations on newt lens regeneration in vitro: Stimulation by thyrotropin. Dev. Biol., 81:2335.

Cuny, R., S.E. Zalik, and E. Dimitrov (1985) Comparison of newt lens regeneration stimulating activity in preparations of mammalian thyrotropin and fibroblast growth factor purified by various methods. Exp. Eye Res., 41:629-637.

Cuny, R., S.E. Zalik, and E. Dimitrov (1984) Trophic stimulation of conversion of cultured newt iris cells into lens cells by a bovine thyrotropin preparation. Can J. Zool., 62:862-869.

Eguchi, G. (1967) In vitro analysis of Wolffian lens regeneration. Differentiation of the developing lens rudiment of the newt, Triturus pyrrhogaster. Embryologia, 9:246-266.

Eisenberg-Zalik, S. and V. Scott (1969) In vitro development of the regenerating lens. Dev. Biol., 19:368-383.

Ezban, M., J.H. Nielsen, and K.W. Kastrub (1979) Possible role of transferrin as carrier for NSILA in serum. In: Somatomedins and Growth. G. Giordano, J. Van Wyk, J and F. Minuto, eds. Academic Press, NY, pp. 189-212.

Gospodarowicz, D., G. Neufeld, and L. Schweigerer (1986) Molecular and biological characteristics of fibroblast growth factor, an angiogenic factor which also controls the proliferation and differentiation of mesoderm and neuroectoderm derived cells. (Review). Cell Differ. 19:117.

Jauker, F. and T. Yamada (1973) Progressive alterution in the pattern of nucleic acid metabolism in the newt iris in cultivation. J. Exp. Zool., 183:145-157.

Lillie, J.H., D.K. MacCallum, and A. Jepsen (1982) The behavior of subcultivated stratified squamous epithelial cells on reconstituted extracellular matrices: Initial interactions. Eur. J. Cell Biol., 29:50-60.

McAvoy, J.W. (1981) Developmental biology of the lens. In: Mechanisms of Cataract Formation in the Hurnan Lens. G. Duncan, ed. Academic Press, pp. 7-46.

Mescher, A.L. and S.I. Munaim (1984) "Trophic" effect of transferrin on amphibian limb regeneration blastemas. J. Exp. Zool., 230:485-490. 
Munaim, S.I. and A.L. Mescher (1986) Transferrin and the trophic effect of neural tissue on amphibian limb regeneration blastemas. Dev. Biol., 116:138-142.

Plouet, J., J. Courty, M. Olivie, Y. Courtojs, and D. Barritault (1984) Highly reliable and sensitive assay for the purification of cellular growth factors. Cell. Mol. Biol., 30:105-110.

Reddan, J.R. and D.C. Dziedzic (1982) Insulin-like growth factors, IGF-1, IGF-2 and somatomedin c trigger cell proliferation in mammalian epithelial cells cultured in a serum-free medium. Exp. Cell Res., 142:293-300.

Reese, D.H. (1973) In vitro initiation in the newt iris of some early inolecular events of lens regeneration. Exp. Eye Res., 17:435-444.

Reese, D.H., E. Puccia, and T. Yamada (1969) Activation of ribosomal RNA synthesis in initiation of Wolffian lens regeneration. J. Exp. Zool., 17:259-268.

Reese, D.H., 'T. Yamada, and R. Moret (1976) An established cell line from the newt, Notophthalmus viridescens. Differentiation, 6:75-81.

Reyer, R.W. (1966) The influence of neural retina and lens on lens regeneration from dorsal iris implants in Triturus viridescens larvae. Dev. Biol., 14:214-225.

Reyer, R.W. (1971) DNA synthesis and the incorporation of labeled iris cells into the lens during lens regeneration in adult newts. Dev. Biol., 24:535-558.

Rothstein, H., J.J. Van Wyk, J.H. Hayden, S.R. Gordon, and A. Weinsieder (1980) An in vivo study with somatomedin-C: Restoration of cycle traverse in $\mathrm{G} 0 / \mathrm{G} 1$ blocked cells of hypophysectomized animals. Science, 208:410-412.

Rounds, D.E. (1973) Adult amphibian tissues and leukocytes. In: Tissue Culture: Methods and Applications. P.F. Kruse, and M.K. Patterson, eds. Academic Press, pp 129-133.

Schreiber S.B., J. Kenney, J. Kowalski, K.A. Thomas, G.
Gimenez-Gallo, M. Rios-Candelore, J. DiSalvo, D. Barritault, J. Courty, Y. Courtois, M. Moenner, C. Loret, W.H. Burgess, T. Mehlman, R. Friesel, W. Johnson, and T. Maciag (1985) A unique family of endothelial cell polypeptide mitogens: The antigenic and receptor cross-reactivity of bovine endothelial cell growth factor, brain derived acidic fibroblast growth factor, and eye derived growth factor-II. J. Cell Biol., 101:16231626.

Stone, L.S. (1958) Inhibition of lens regeneration in newt eyes by isolating the dorsal iris from the neural retina. Anat. Rec., 131:151-172.

Stone, L.S. and H. Steinitz (1953) The regeneration of lenses in eyes with intact and regenerating retina in adult newt Triturus $v$, viridescens, J. Exp. Zool, 124:435-468.

Williams, L.A. and M. McGlinn (1979) Stimulation of lens regeneration in vitro, by growth factors and spinal ganglia. Am. Zool., 19:923.

Yamada, T. (1967) Cellular and subcellular events in Wolffian lens regeneration. Curr. Top. Dev. Biol., 2:247-283.

Yamada, T. (1982) Transdifferentiation of lens cells and its regulation. In: Cell Biology of the Eye. D.S. McDevitt, ed. Academic Press, pp 193-242.

Yamada, T. (1984) Developmental control of cell differentiation. Zool. Sci., 1:333-348.

Yamada, T. and McDevitt, D.S. (1984) Conversion of iris epithelial cells as a model of differentiation control. Differentiation, 27: 1-12.

Yamada, T., D.H. Reese, and D.S. McDevitt (1973) Transformation of iris into lens in vitro and its dependency on the neural retina. Differentiation, 1:65-82.

Zalokar, M. (1944) Contributions a l'etude de la regeneration du cristallin chez le Triton, Rev. Suisse Zool., 51:444-521. 